\title{
Development of the "Treatment beliefs in knee and hip OsteoArthritis (TOA)" questionnaire
}

\author{
Ellen M. H. Selten ${ }^{1 *}$, Johanna E. Vriezekolk' ${ }^{1}$, Henk J. Schers ${ }^{2}$, Marc W. Nijhof ${ }^{3}$, Willemijn H. van der Laan ${ }^{4}$ \\ Roelien G. van der Meulen-Dilling ${ }^{5}$, Rinie Geenen ${ }^{6}$ and Cornelia H. M. van den Ende ${ }^{1}$
}

\begin{abstract}
Background: Use of conservative treatment modalities in osteoarthritis (OA) is suboptimal, which appears to be partly due to patients' beliefs about treatments. The aim of this study was to develop a research instrument assessing patients' beliefs about various treatment modalities of hip and knee OA: the 'Treatment beliefs in OA (TOA) questionnaire'.

Methods: The item pool that was retrieved from interviews with patients and healthcare providers comprised beliefs regarding five treatment modalities: physical activity, pain medication, physiotherapy, injections and arthroplasty. After an extensive selection procedure, a draft questionnaire with 200 items was constructed. Descriptive analyses and exploratory factor analyses with oblique rotation were conducted for each treatment modality separately to decide upon the final questionnaire. Internal consistency and test-retest reliability were determined.

Results: The final questionnaire comprised 60 items. It was completed by 351 patients with knee or hip OA. Each of the five treatment modalities yielded a two factor solution with $37 \%$ to $51 \%$ explained variance and high face validity. Factor I included 'positive treatment beliefs' and factor II 'negative treatment beliefs'. Internal consistency (Cronbach a's from 0.72 to 0.87 ) and test-retest reliability (i.e. intraclass correlation coefficient from 0.66-0.88; standard error of measurement from 0.06-0.11) were satisfactory to good.

Conclusions: The TOA questionnaire is the first questionnaire assessing positive and negative treatment beliefs regarding five treatment modalities for knee and hip OA. The instrument will help to understand whether and to what extent treatment beliefs influence treatment choices.
\end{abstract}

Keywords: Osteoarthritis, Knee, Hip, Treatment beliefs, Measurement instrument

\section{Background}

Osteoarthritis (OA) of the knee and hip causes pain, stiffness and decreased physical functioning [1]. Because OA cannot be cured, treatment is directed towards the reduction of symptoms, improvement of quality of life, and prevention of progression. Treatment options can be classified into conservative treatment modalities, such as lifestyle education, pain medication and physiotherapy,

\footnotetext{
*Correspondence: e.selten@maartenskliniek.nl

'Department of Rheumatology, Sint Maartenskliniek, Sint Maartenskliniek, P.O. Box 9011, 6500, GM, Nijmegen, The Netherlands

Full list of author information is available at the end of the article
}

and surgical treatment modalities, such as an arthroplasty and osteotomy [1].

Several national and international recommendations and guidelines for the management of hip and knee OA recommend that patients first are provided with conservative treatment options, and that they are referred to surgical treatment only when conservative treatment does not lead to adequate pain relief and functional improvement [2-4]. However, in clinical practice, health care utilisation is suboptimal in terms of underutilisation of conservative treatment modalities [5-7] and an increased use of surgical treatment modalities [8]. This is undesirable because surgery does not always result in 
good outcomes and pain reduction $[9,10]$ and may lead to higher health care costs.

Amongst others, a possible pathway to optimise the imbalanced use of treatment options is through understanding patients' beliefs about treatment modalities of knee and hip OA [11, 12]. Patients' beliefs influence health-related behaviour as postulated by health beliefs models, such as the Theory of Planned Behaviour [13]. Previous research found that patients' beliefs about the efficacy and safety of medication influence both their decision to take medication and their preference for the type of medication [14]. Moreover, it has been suggested that treatment choices can be better predicted when beliefs about multiple treatment options are assessed, instead of assessing beliefs about a single treatment option [15]. Therefore, identifying patients' beliefs about various treatment modalities of OA may help to increase the understanding of treatment decisions.

At present, little is known about how and to what extent patients' beliefs about treatment modalities of knee and hip OA influence patients' treatment choices. Previous qualitative studies indicate that many considerations such as patients' beliefs about the effectiveness and side-effects of the treatment may play a role in their treatment choice [16-18]. While qualitative studies are ideal to get an encompassing overview of all possible determinants of treatment choices, a measurement instrument based on self-reports is needed to get insight into the relative importance of treatment beliefs in the one patient as compared to the other. Therefore, guided by the results of these qualitative studies, a self-report instrument is needed in order to be able to systematically assess patients' beliefs about treatment modalities for knee and hip OA. This instrument can be used in research to examine to what extent patients' treatment beliefs contribute to the patients' decision making process, and ultimately help to understand why conservative treatment modalities are underused in the management of knee and hip OA.

In the context of knee and hip OA, no questionnaire is available that comprehensively assesses patients' beliefs about both surgical and conservative treatment modalities. Existing questionnaires assess fears and beliefs related to the consequences of knee OA [19] and expectations about the role of their physician in the management of knee OA [20]. Existing self-report instruments about treatment beliefs refer to low back pain [21], medicines [22] and surgery [15]. Therefore, the aim of the current study was to develop a questionnaire to assess patients' beliefs about treatment modalities of knee and hip OA: the TOA (Treatment beliefs in OsteoArthritis) questionnaire, and to examine its factorial structure, internal consistency and test-retest reliability.

\section{Methods}

\section{Development of item pool}

For the development of a first draft of the TOA questionnaire an elaborated process was undertaken to generate and select items based on the findings of three previous studies among patients with knee and hip OA in the Netherlands. These were two qualitative studies $[17,23]$ on treatment beliefs in patients and healthcare providers and a concept mapping study [24] to define the most important themes. A total of 2207 statements reflecting beliefs about treatment modalities of knee or hip OA (which could be potentially included as items in the TOA questionnaire) were extracted from the interviews. Items were selected from 4 major themes originated from the concept mapping study: 'contextual barriers' (e.g. the healthcare system), disadvantages (e.g. risks), treatment outcomes (e.g. physical functioning) and 'outcomes for personal life' (e.g. activities of daily living) [24].

The draft TOA questionnaire consisted of five modules, based on five treatment options recommended in the 'stepped care strategy' for knee and hip OA in the Netherlands [3]: physical activities, pain medication, physiotherapy, injections and arthroplasty. We aimed for a feasible set of approximately 50 items to include in each module in the draft version of the TOA questionnaire. In a careful and thorough consensus process, as described previously [24], all 2207 statements about specific treatment modalities derived from the interviews were reduced by a project group comprising researchers and health professionals including medical specialists. The selection procedure comprised several steps. For each step, cut-off points were developed to reach a representative set of 51 general items (Additional file 1). Two patient partners assessed this set of 51 items for its representativeness and comprehensiveness. In the next step, all 51 items were assessed for its applicability to each of the 5 treatment modalities. For instance, the item 'the treatment may cause an infection' was applicable for the treatment modality injections and arthroplasty, but not for physical activity, pain medication and physiotherapy. If applicable, the item was included in the module. The final draft version of the TOA questionnaire comprised 200 items, distributed over 5 modules: physical activities (41 items), pain medication (37 items), physiotherapy (42 items), injections (41 items) and arthroplasty (39 items). A 5-point Likert scale with scoring options ranging from 1 to 5 was chosen, labelled from 'disagree' to 'agree' in order to avoid endaversion bias (i.e. avoiding absolute statements as 'completely disagree' and 'completely agree' to overcome the reluctance of some people to use extreme categories of a scale) [25]. The TOA questionnaire was developed in Dutch. An English translation of the items can be found in Additional file 2. 


\section{Pilot testing}

The draft TOA questionnaire was pilot tested in a stepwise way. The first draft of the questionnaire was tested by five researchers and health professionals. Subsequently, ten patients were recruited via a primary care physiotherapy practice in the Northern part of the Netherlands. Besides the clinical diagnosis of knee or hip OA, no other inclusion criteria were required. Patients were asked to fill out the questionnaire at home and to make notes if they thought a question was difficult to understand. Hereafter, the researcher contacted the patient for a telephone interview. All items of the questionnaire were discussed, using the probing method for pilot-testing whether the patient understood the items, whether items were interpreted according to their intended meaning, and whether the length of the questionnaire was considered acceptable $[26,27]$. Including patients for the pilot test was stopped after 10 interviews because no new information emerged from interviewing the last two patients (data saturation). Based on the results of the pilot test, minor alterations were made in the instructions and lay-out.

\section{Patients and measures}

Two different samples were recruited for this study. The first sample was recruited to examine the factor structure and internal consistency of the TOA questionnaire; the second sample was recruited to examine the test-retest reliability of the TOA questionnaire.

\section{Sample 1: Factor structure and internal consistency}

Eligible patients who visited the department of Rheumatology of the Sint Maartenskliniek in 2013-2014 $(n=600$, randomly selected from the electronic patient record system) or the department of Orthopaedics in June-August 2015 ( $n=240$, consecutively), who were clinically diagnosed with knee or hip OA, and were aged $\geq 18$ received an information letter and informed consent form. Assuming a number of 4-10 participants per item and 51 unique items, a sample size of at least 204 patients was needed to perform the factor analysis [26]. These patients filled out the TOA questionnaire once. In addition, demographic and clinical characteristics were collected: body mass index (BMI), duration of OA symptoms, affected joint(s), comorbidities (question 70 from the DUTCH-AIMS2 [28]), treatment use, and the Dutch version of the Western Ontario and McMaster Universities Arthritis LK3.1 Index (WOMAC). The WOMAC is a health status measure assessing the dimensions of pain, stiffness and function in patients with OA of the hip/knee [29].

\section{Sample 2: Test-retest reliability analysis}

Patients were consecutively selected from a larger study sample with similar eligibility criteria as sample 1 . To determine test-retest reliability by calculating an ICC of 0.8 with a $95 \%$ confidence interval \pm 0.1 using 2 repeated measurements, 50 respondents are required [26]. Eligible patients of the department of Rheumatology of the Sint Maartenskliniek in 2015-2016 $(n=39)$ or the department of Orthopaedics in September 2015-September $2016(n=41)$ were randomly selected from the electronic patient record system. Patients were invited to fill out the final TOA questionnaire twice, with a 2 weeks interval. The first 50 respondents who sent the questionnaire back were included in the analysis, to keep the time between the first and second measurement close to the aimed interval of 2 weeks.

The medical ethical board of the Radboud University Medical Center, Nijmegen concluded that the Dutch Medical Research Involving Human Subjects Act did not apply to this study (protocol number: 2015-1772 for sample 1 and protocol number 2016-2605 for sample 2).

\section{Statistical analyses}

Because the TOA questionnaire comprises five treatment modalities, we aimed for a brief set of items per treatment module. Therefore, rigorous item reduction and exploratory factor analysis were used to design the final TOA questionnaire. This was conducted per module in three consecutive steps: initial item reduction, factor analysis and further refinement. Furthermore, internal consistency (Cronbach's alpha) and the test-retest reliability of the final TOA questionnaire were examined per module.

\section{Step 1: Initial item reduction}

Items were considered to be deleted if: a) missing values were $>15 \%$; b) $>50 \%$ of patients scored 1 (disagree) or 5 (agree) on an item (floor or ceiling effect); c) skewness of the item was $>1$; d) inter-item correlations were $>.80$ (in this case one of the redundant paired items was considered for deletion) [25].

\section{Step 2: Factor analysis and internal consistency}

Exploratory factor analyses were conducted for each modality separately to examine the dimensionality of the TOA questionnaire. First, exploratory factor analysis without rotation was used to determine the initial numbers of factors. This was determined by two researchers (JV and ES) by visual inspection of the scree plot, percentages of explained variance $(>5 \%)$ and eigenvalues $>1$ [30]. Thereafter, for each module exploratory factor analysis with oblique (direct oblimin) rotation was conducted for 2-factor to 4factor solutions. Oblique rotation was chosen because it allowed the extracted factors to be correlated. To select the most salient items two criteria were used: only items with factor loadings $\geq 0.45$ were retained, and items with cross loadings on more than one factor within 0.3 of the primary loading were dropped because 
of inadequate discrimination [31]. The final number of factors per module was determined by the project group based on factor interpretability and revealed a 2factor solution for each module.

\section{Step 3: Further refinement}

Guided by the results of a previous concept mapping study [24], items were further considered for deletion. Briefly, in this concept mapping study, 36 patients sorted the 51 items (each item printed on a card) from the TOA questionnaire into piles with a similar meaning; subsequently hierarchical cluster analysis yielded a 15-cluster solution that was grouped in 4 higher-order categories and 2 overarching categories. The following additional rules (set by the project group) were applied for further item reduction per module:

1. Each factor should contain preferably a maximum of 1 item per cluster

2. If more than 1 item per cluster loaded on the factor, the item with the highest factor loading was retained

3. If internal consistency of a factor, as assessed with Cronbach's alpha, dropped below .70, the item with the next highest factor loading was retained.

4. If internal consistency of the factor, as assessed with Cronbach's alpha, was still $<.70$, an item with the next highest factor loading from another cluster was added.

Lastly, a final two-factor factor analysis with the remaining items per module was conducted. Cronbach's alpha was calculated for each factor, and Pearson's correlation coefficients were calculated between factor I and factor II per module.

\section{Test-retest reliability}

Because each method to assess test-retest reliability of a questionnaire has its advantages and disadvantages and is difficult to interpret without other methods [32], multiple methods were used to assess the test-retest reliability of the TOA questionnaire. Test-retest reliability was determined by 1) Intraclass correlation coefficients (ICCs) (two-way mixed effects model, measuring consistency of individual differences) [33]; 2) Limits of agreement (LoA); and 3) Standard errors of measurement (SEMs) of the whole model including systematic differences between repeated measures. Scale scores of the TOA questionnaire were calculated by summation of the items for each factor. When a respondent had $\leq 25 \%$ missing items on a subscale, these missing items were substituted by the respondent's mean sum score on the subscale. When a respondent had $>25 \%$ missing items on a subscale, these were taken into account as missing values in the analysis. Unstandardised scores for each subscale per module were used for calculating ICCs and the LoA. For calculating the SEM, standardised scores were calculated (raw total score of subscale / total items on subscale). Thus, total scores on each subscale were comparable on a scale from 1 to 5 . ICCs range from 0 to 1 , whereby 1 reflects perfect reliability. In general, ICCs $\geq 0.70$ are considered acceptable [34]. LoA were calculated with the following formula: mean difference $\pm 1.96 \times \mathrm{SD}_{\text {difference. }}$ SEM of the whole model including systematic variation of repeated measures was calculated for each subscale with: $\sqrt{ }\left(\sigma_{m}^{2}+\sigma_{\text {residual }}^{2}\right)$. Where $\sigma_{m}^{2}=$ variance between the two repeated measures; and $\sigma_{\text {residual }}^{2}=$ variance of the residual ("error"). A smaller SEM reflects better test-retest reliability [26].

All analyses were performed using STATA 13.1.

\section{Results}

Participants

Sample 1

Of 840 invited patients, 351 filled out the TOA questionnaire and provided informed consent (response rate: $41.8 \%)$. Eighty-two patients indicated they did not want to participate in the study. Some patients provided a reason for non-participation, e.g.: no knee or hip OA $(n=25)$, not wanting to $(n=5)$, comorbidities $(n=4)$, not satisfied about care provided by the hospital $(n=3)$. Ten patients who did fill out the questionnaire were excluded because they did not provide informed consent. Three patients did not fill out the additional questionnaire assessing demographic and clinical characteristics but were included in the factor analysis. Table 1 shows the demographic and clinical characteristics of the study sample.

\section{Sample 2}

Of the 80 patients who were invited to fill out the final TOA questionnaire twice, 67 patients returned the questionnaire (response rate: $83.8 \%$ ). The first 50 respondents who sent the questionnaire back were included in the analysis, to keep the time between the first and second measurement close to the aimed interval of 2 weeks (Mean time interval $=13$ days, $\mathrm{SD}=2.5$, range $=6-18$ ). The mean age of sample 2 was 63.8 years $(\mathrm{SD}=10.5)$, and $56 \%$ was female.

\section{Step 1: Initial item reduction}

Item reduction resulted in dropping $9,8,8,2$, and 4 items respectively in modules 1 to 5 . Two pairs of items in module 4 had a correlation of 0.81 and 0.82 , but because the items reflected different contents, none of the items were deleted.

\section{Step 2: Factor structure and internal consistency}

Based on exploratory factor analyses and interpretability, a two-factor solution for each module was obtained. 
Table 1 Characteristics of the study sample $\left(N=348^{\mathrm{a}}\right)$

\begin{tabular}{|c|c|}
\hline \multicolumn{2}{|l|}{ Demographic characteristics } \\
\hline Age (years), mean (SD) & $62.8(12.3)$ \\
\hline Gender (female), $n$ (\%) & $217(63.1)$ \\
\hline Married or cohabiting, $n(\%)$ & $273(79.4)$ \\
\hline Currently employed, $n(\%)^{b}$ & $145(44.1)$ \\
\hline \multicolumn{2}{|l|}{ Education level, $n(\%)^{c}$} \\
\hline Low & $62(18.0)$ \\
\hline Middle & $175(50.9)$ \\
\hline High & $107(31.1)$ \\
\hline \multicolumn{2}{|l|}{ Clinical characteristics } \\
\hline \multicolumn{2}{|l|}{ Body Mass Index (BMI) (kg/m²), n(\%) } \\
\hline Normal weight (BMI <25) & $106(31.0)$ \\
\hline Overweight (BMI 25-30) & $146(42.7)$ \\
\hline Obese (BMI > 30) & $90(26.3)$ \\
\hline Duration of OA symptoms (years), mean $(\mathrm{SD})^{b}$ & $11.1(9.8)$ \\
\hline \multicolumn{2}{|l|}{ Affected joint(s), $n(\%)$} \\
\hline Hip & $82(24)$ \\
\hline Knee & $169(49.5)$ \\
\hline Hip and knee & $91(26.5)$ \\
\hline \multicolumn{2}{|l|}{ Comorbidities, $\mathrm{n}(\%)^{d}$} \\
\hline No comorbidities & $141(40.8)$ \\
\hline High blood pressure & $97(28.0)$ \\
\hline Heart disease & $39(11.2)$ \\
\hline Diabetes & $27(7.8)$ \\
\hline Lung disease & $28(8)$ \\
\hline Other & $42(12)$ \\
\hline \multicolumn{2}{|l|}{ Previous or current treatments for $\mathrm{OA}, n(\%)^{d}$} \\
\hline Pain medication & $291(85.3)$ \\
\hline Physiotherapy & $234(68.6)$ \\
\hline Injections & $133(39.0)$ \\
\hline Surgery & $112(32.8)$ \\
\hline \multicolumn{2}{|l|}{$\begin{array}{l}\text { WOMAC (Likert scale } 0-4) \text {, unstandardized } \\
\text { mean (SD), theoretical range }\end{array}$} \\
\hline Pain $^{b}$ & $10.0(4.5), 0-20$ \\
\hline Stiffness & $4.5(2.0), 0-8$ \\
\hline Functioning & 32.4 (14.8), 0-68 \\
\hline Total (sum score) ${ }^{b}$ & $46.7(20.0), 0-96$ \\
\hline
\end{tabular}

a 3 respondents did not fill out these questions

${ }^{\mathrm{b}}$ Missing values $>5 \%$ : Currently employed $=6 \%$; Duration of OA

symptoms $=7 \%$; WOMAC subscale pain $=5 \%$, WOMAC total (sum score) $=8 \%$

'Low = no education, primary school, lower vocational education;

Middle = secondary school, middle vocational education; High $=$ higher

vocational education, university

${ }^{\mathrm{d}}$ More than 1 answer possible

eWestern Ontario and McMaster Universities Arthritis Index. Higher scores

reflect worse pain, stiffness and functioning

Respectively $8,12,16,18,14$ items were dropped because of factor loadings $\geq 0.45$ or cross loadings $<0.3$ in module 1 to 5 (Additional file 2).
Step 3: Further refinement

After the previous steps of item reduction, a total of 24 , 17, 18, 22 and 21 items remained for module 1 to 5 respectively). After the third step of refinement, 13 items remained for module 1 (physical activities), 12 items for module 2 (pain medication), 9 items for module 3 (physiotherapy), 12 items for module 4 (injections), and 14 items for module 5 (arthroplasty). After this last round of item reduction, a final 2-factor factor analysis with oblique (direct oblimin) rotation was performed for all modules. The explained percentage of variance per module ranged from $37 \%$ to $51 \%$, Cronbach's alpha's of the final TOA questionnaire ranged from .72 to .87 , and correlations between factors ranged from -.03 to -.51 (Table 2).

\section{Factor interpretation}

For each module, the first factor reflected positive beliefs about the treatment, such as health benefits and perceived advantages (e.g. "I learn to deal with my symptoms better by the treatment"). The second factor reflected negative beliefs about the treatment, such as treatment risks and disadvantages (e.g. "I think that the treatment involves risks"). Therefore, for each module, Factor I was labelled 'positive treatment beliefs' and Factor II was labelled 'negative treatment beliefs'. For each subscale in each module of the TOA questionnaire, a sum score can be calculated whereby a higher sum score on subscale I reflects more positive treatment beliefs and a higher sum score on subscale II reflects more negative treatment beliefs. Scorings on the questions M5Q4 and M5Q9 should be reversed. Missing item scores on a subscale are replaced with the mean of the other items; when more than $25 \%$ of the items are missing, the subscale score is not valid.

Table 2 presents the factor loadings, eigenvalues, percentages of explained variance, Cronbach's alpha for each factor per treatment module, and the correlations between factors per treatment module.

\section{Test-retest reliability}

Table 3 shows 3 different measures of test-retest reliability for each subscale of the TOA questionnaire. Considering the moderate to high ICCs $(0.66-0.88)$ and small SEM (0.06-0.11) obtained for all subscales, test-retest reliability of the TOA questionnaire was satisfactory.

\section{Discussion}

The TOA questionnaire is the first questionnaire assessing treatment beliefs regarding surgical and conservative (physical activities, pain medication, physiotherapy, injections) modalities for knee and hip OA. The TOA questionnaire comprises five treatment modalities with each a positive and negative subscale. Each part of the 
Table 2 Factor loadings, eigenvalues, percentage of explained variance and Cronbach's alpha for the final TOA questionnaire Module 1: Physical activities

Items

$M 1=$ Module 1, $Q=$ Question number (see Additional file 1)

M1Q32: I learn to deal with my symptoms better by doing physical activities

M1Q19: I can do household chores better by doing physical activities

M1Q22: Doing physical activities produces good results at my age

M1Q33: I can do my job better by doing physical activities

M1Q39: I can tailor doing physical activities to my goals

M1Q10: I can postpone surgery by doing physical activities

M1Q14: I can do physical activities together with others

M1Q8: The only way to reduce my OA symptoms is by doing physical activities M1Q20: I enjoy doing physical activities

M1Q24: By doing physical activities I will overload my knee/hip

M1Q23: I think that doing physical activities causes pain

M1Q7: I think that doing physical activities involves risks

M1Q28: I am scared to do physical activities

Eigenvalue

Percentage of variance

Cronbach's Alpha

Correlation between factors

Module 2: Pain medication

Items

M2 = Module 2, $Q=$ Question number (see Additional file 1)

M2Q10: I can move more freely by using painkillers

M2Q18: I can do household chores better by using painkillers

M2Q2: My quality of life increases by using painkillers

M2Q20: Using painkillers produces good results at my age

M2Q9: I can postpone surgery by using painkillers

M2Q15: Using painkillers is harmful to my health

M2Q6: I think that using painkillers involves risks

M2Q11: I think that painkillers have side-effects

M2Q28: I think that using painkillers is invasive

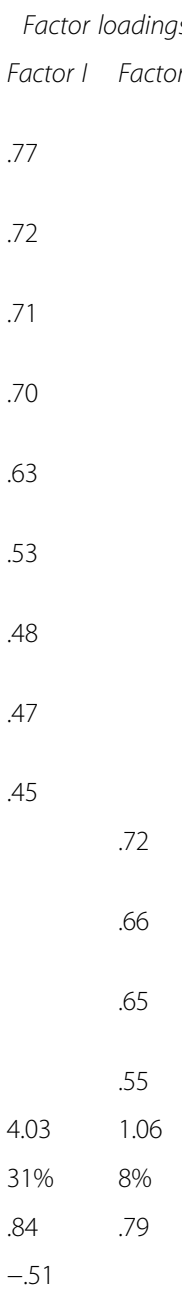

Factor loadings

Factor I Factor II

.80

.76

.74

.73

.50

.67

.64

.52
Table 2 Factor loadings, eigenvalues, percentage of explained variance and Cronbach's alpha for the final TOA questionnaire (Continued)

\begin{tabular}{lll}
\hline M2Q25: I am scared to use painkillers & .47 \\
M2Q19: I think that using painkillers & .38 \\
leads to habituation & & \\
M2Q22: By using painkillers I will overload & & .35 \\
my knee/hip & & \\
Eigenvalue & 2.74 & 2.00 \\
Percentage of variance & $23 \%$ & $17 \%$ \\
Cronbach's Alpha & .82 & .72 \\
Correlation between factors & -.14 &
\end{tabular}

Module 3: Physiotherapy

Items

Factor loadings

M3 = Module 3, $Q=$ Question number

(see Additional file 1)

M3Q23: Doing physiotherapy produces

good results at my age

M3Q20: I can do household chores

better by physiotherapy

M3Q34: I can do my job better by

physiotherapy

M3Q3: My quality of life increases by physiotherapy

M3Q22: I need to actively get going

with physiotherapy myself

Factor I Factor II

.86

.85

.76

.71

.60

M3Q10: I can postpone surgery by

physiotherapy

.52

M3Q25: By physiotherapy I will overload

.71

my knee/hip

M3Q24: I think that physiotherapy causes pain

.70

M3Q7: I think that physiotherapy involves risks

.62

Eigenvalue

$3.49 \quad 1.09$

Percentage of variance

$39 \% \quad 12 \%$

Cronbach's Alpha

$.86 \quad .74$

Correlation between factors

$-.36$

Module 4: Injections

Items

M4 = Module 4, Q = Question number

(see Additional file 1)

M4Q33: I can do my job better by an injection

M4Q20: I can do household chores better by an injection

M4Q3: My quality of life increases by an injection

M4Q30: An injection gives quick results $\quad .76$

M4Q10: I can postpone surgery by an $\quad .62$ injection

M4Q31: I think that an injection can be repeated

\section{Factor loadings}

Factor I Factor II 
Table 2 Factor loadings, eigenvalues, percentage of explained variance and Cronbach's alpha for the final TOA questionnaire (Continued)

\begin{tabular}{|c|c|c|}
\hline $\begin{array}{l}\text { M4Q24: By an injection I will overload } \\
\text { my knee/hip }\end{array}$ & & .62 \\
\hline $\begin{array}{l}\text { M4Q15: I am becoming dependent on } \\
\text { an injection }\end{array}$ & & .61 \\
\hline M4Q34: An injection damages my knee/hip & & .60 \\
\hline M4Q32: I think that an injection is invasive & & .54 \\
\hline M4Q7: I think that an injection involves risks & & .48 \\
\hline M4Q40: An injection takes a lot of my time & & .38 \\
\hline Eigenvalue & 3.54 & 1.78 \\
\hline Percentage of variance & $30 \%$ & $15 \%$ \\
\hline Cronbach's Alpha & .87 & .72 \\
\hline Correlation between factors & -.11 & \\
\hline \multicolumn{3}{|l|}{ Module 5: Arthroplasty } \\
\hline Items & Factor 1 & oadings \\
\hline $\begin{array}{l}\text { M5 = Module } 5, Q=\text { Question number } \\
\text { (see Additional file 1) }\end{array}$ & Factor 1 & Factor II \\
\hline $\begin{array}{l}\text { M5Q4: My pain increases by a joint } \\
\text { replacement }\end{array}$ & -.61 & \\
\hline $\begin{array}{l}\text { M5Q9: My knee/hip deteriorates faster } \\
\text { by a joint replacement }\end{array}$ & -.51 & \\
\hline $\begin{array}{l}\text { M5Q10: I can move more freely after a } \\
\text { joint replacement }\end{array}$ & .78 & \\
\hline $\begin{array}{l}\text { M5Q17: I can do household chores better } \\
\text { after a joint replacement }\end{array}$ & .77 & \\
\hline $\begin{array}{l}\text { M5Q18: A joint replacement produces } \\
\text { good results at my age }\end{array}$ & .81 & \\
\hline $\begin{array}{l}\text { M5Q21: More people with OA choose to } \\
\text { do a joint replacement }\end{array}$ & .43 & \\
\hline $\begin{array}{l}\text { M5Q29: I think that a joint replacement } \\
\text { can be repeated }\end{array}$ & .45 & \\
\hline $\begin{array}{l}\text { M5Q38: I think that an artificial joint lasts a } \\
\text { long time }\end{array}$ & .44 & \\
\hline M5Q1: I think a joint replacement is painful & & .51 \\
\hline $\begin{array}{l}\text { M5Q23: I think an artificial joint carries the } \\
\text { chance of an infection }\end{array}$ & & .57 \\
\hline $\begin{array}{l}\text { M5Q24: I think a joint replacement carries } \\
\text { the chance of an infection }\end{array}$ & & .67 \\
\hline $\begin{array}{l}\text { M5Q27: A joint replacement takes up my } \\
\text { energy }\end{array}$ & & .53 \\
\hline $\begin{array}{l}\text { M5Q30: I think that a joint replacement is } \\
\text { invasive }\end{array}$ & & 62 \\
\hline $\begin{array}{l}\text { M5Q37: A joint replacement takes a lot of } \\
\text { my time }\end{array}$ & & 60 \\
\hline Eigenvalue & 3.13 & 2.14 \\
\hline Percentage of variance & $22 \%$ & $15 \%$ \\
\hline Cronbach's Alpha & .81 & .75 \\
\hline Correlation between factors & -.03 & \\
\hline
\end{tabular}

Table 3 Intraclass correlation coefficient (ICC), mean difference between repeated measures, limits of agreement (LOA), and standard error of measurement (SEM) including systematic differences between repeated measures and error variance

\begin{tabular}{|c|c|c|c|c|c|}
\hline Module & Subscale & ICC & Mean difference & LoA & SEM \\
\hline \multirow[t]{2}{*}{ Physical activity } & $\begin{array}{l}\text { positive } \\
9 \text { items }\end{array}$ & .88 & -.44 & $-7.65 ; 6.78$ & .06 \\
\hline & $\begin{array}{l}\text { negative } \\
4 \text { items }\end{array}$ & .74 & .81 & $-4.60 ; 6.23$ & .10 \\
\hline \multirow[t]{2}{*}{ Pain medication } & $\begin{array}{l}\text { positive } \\
5 \text { items }\end{array}$ & .80 & .19 & $-6.44 ; 6.82$ & .09 \\
\hline & $\begin{array}{l}\text { negative } \\
7 \text { items }\end{array}$ & .83 & .59 & $-6.82 ; 8.00$ & .08 \\
\hline \multirow[t]{2}{*}{ Physiotherapy } & $\begin{array}{l}\text { positive } \\
6 \text { items }\end{array}$ & .88 & .16 & $-6.35 ; 6.67$ & .08 \\
\hline & $\begin{array}{l}\text { negative } \\
3 \text { items }\end{array}$ & .72 & -0.40 & $-4.81 ; 4.01$ & .11 \\
\hline \multirow[t]{2}{*}{ Injections } & $\begin{array}{l}\text { positive } \\
6 \text { items }\end{array}$ & .88 & 0.05 & $-5.85 ; 5.96$ & .07 \\
\hline & $\begin{array}{l}\text { negative } \\
6 \text { items }\end{array}$ & .83 & .45 & $-5.06 ; 5.96$ & .07 \\
\hline \multirow[t]{2}{*}{ Arthroplasty } & $\begin{array}{l}\text { positive } \\
8 \text { items }\end{array}$ & .66 & -.20 & $-9.14 ; 8.75$ & .08 \\
\hline & $\begin{array}{l}\text { negative } \\
6 \text { items }\end{array}$ & .77 & .45 & $-5.52 ; 6.41$ & .07 \\
\hline
\end{tabular}

questionnaire can be used independently, so beliefs regarding either one or multiple treatment modalities can be measured. A main strength of this study was the design used to generate the items. For the selection of items, we used two previous in-depth interview studies in which both patients and healthcare providers were asked about their beliefs and views regarding treatment modalities for knee and hip OA [17, 23]. The item pool was generated very carefully in several consensus rounds by the project team, and selected items were assessed by patients. As a result, based on the perspective of patients and professionals, we developed a questionnaire to comprehensively assess both positive and negative treatment beliefs in knee and hip OA. The qualitative approach will have contributed to the face validity. The internal consistency and test-retest reliability of the TOA questionnaire were satisfactory to good. Confirmatory factor analysis and replication of clinimetric properties in other samples as well as validation studies such as studies examining the association with actual treatment choices are needed in order to fully establish the validity and reliability of the TOA questionnaire.

The 2-factor structure reflected individual differences in positive and negative beliefs about treatment modalities. Similarly to existing generic questionnaires about medication (Beliefs about Medicines Questionnaire (BMQ) [22]) and surgery (Beliefs about Surgery Questionnaire (BSQ) [15]), the TOA questionnaire assesses negative treatment beliefs as a distinct dimension. In contrast to the BMQ 
and BSQ, the TOA questionnaire also assesses positive beliefs about treatment modalities. The small correlations between the factors - especially for the modules pain medication, injections and arthroplasty - show that positive and negative beliefs are not the opposite poles of a single dimension. This indicates the importance of measuring both patients' negative and positive treatment beliefs in order to fully understand patients' treatment preferences.

The TOA questionnaire can primarily be used as a research tool to assess individual differences in treatment beliefs and to examine to what extent treatment beliefs influence treatment choices in OA. Previous research showed that patients with knee or hip OA differ in their willingness to undergo surgery, and that this difference might be due to individual differences in sex, ethnicity, socioeconomic status [35], severity, age and income [36]. In interaction with, and in addition to these sociodemographic characteristics, treatment beliefs will likely play a role in treatment choices, specifically in suboptimal use of conservative treatment modalities. Previous studies have demonstrated the practice variation in primary care settings with regard to diagnostic procedures and referrals [37, 38], and that referrals by the GP to other disciplines are associated with patients' preferences [39]. This suggests that besides organisational and healthcare providerrelated factors, patients' treatment beliefs should be taken into account, in order to choose a treatment that fits best to the patient's individual situation and preferences. In clinical practice, individual scores at the TOA questionnaire could be used as an input for shared decision making. However, users should be aware that the item pool reflects a restricted number of items that predominantly reflect individual differences. To get an encompassing overview of treatment beliefs that may be important for an individual patient, it is better to use all statements from a previous concept mapping study [24] which represent a wide range of potential benefits and barriers.

Some limitations of the study need to be addressed. Firstly, our findings in a secondary care sample cannot be generalised to other samples or settings without empirical replication. With respect to external validity, crosscultural validation studies are needed to examine whether the TOA questionnaire is valid to use in other languages and cultures than Dutch. Also other aspects of validity need to be more extensively evaluated, such as construct validity and criterion validity. In new samples, the structural validity of the TOA questionnaire could be further evaluated by using confirmatory factor analyses to verify whether the factor structure is replicated and ItemResponse Theory to improve the precision of the measurement instrument [26]. On average, our sample reported moderate OA complaints in terms of pain, stiffness and functioning $[29,40]$. Future research needs to examine the robustness of the factor structure of the TOA in other samples. Secondly, the response rate for sample 1 in this study was $42 \%$, which could indicate a response bias. The questionnaire was quite long, which might have been burdensome for patients. The response rate, however, is comparable to other studies in knee or hip OA [41]. Moreover, 351 respondents filled in the questionnaire, which is sufficient for a factor analysis [26]. Thirdly, patients' involvement in the item reduction process for the TOA questionnaire was limited to an assessment of the comprehensiveness and completeness of the items by two patients and an extensive pilot-test in 10 primary care patients. However, items for the TOA questionnaire were selected in a careful and thorough process to enhance the validity of the questionnaire.

\section{Conclusions}

The TOA questionnaire assesses positive and negative treatment beliefs of patients with knee or hip OA about 5 treatment modalities: physical activities, pain medication, physiotherapy, injections and arthroplasty. Initial analyses of the clinimetric properties of the TOA questionnaire are promising. The questionnaire can be used in research to clarify treatment choices. Future research should assess the validity and reliability of the TOA questionnaire in other OA samples, and should verify whether treatment beliefs in interaction with other variables influence intended and actual treatment choices.

\section{Additional files}

Additional file 1: Procedure that was used for selecting a representative set of items from statements resulting from interviews. Description: Procedure that was used for selecting a representative set of items from statements resulting from interviews. (DOCX $22 \mathrm{~kb}$ )

Additional file 2: Initial factor loadings for items in the Treatment beliefs in OsteoArthritis Questionnaire in patients with knee and hip osteoarthritis ( $N=351)$. Description: Initial factor loadings for items in the Treatment beliefs in OsteoArthritis Questionnaire. (DOCX 42 kb)

\section{Abbreviations}

BMI: Body mass index; ICC: Intraclass correlation coefficient; LoA: Limits of agreement; OA: Osteoarthritis; SD: Standard deviation; SEM: Standard error of measurement; TOA: Treatment beliefs in osteoarthritis; WOMAC: Western ontario and McMaster universities arthritis index

\section{Acknowledgements}

Not applicable.

Funding

Not applicable.

\section{Availability of data and materials}

Datasets supporting the conclusions of this article are available and can be requested from the corresponding author.

\section{Authors' contributions}

Study conception and design: ES, JV, CE. Acquisition of data: ES. Contributions to the analysis and interpretation of data: ES; JV; HS; MW; WL; $\mathrm{RM} ; \mathrm{RG} ; \mathrm{CE}$. Drafting the article and revising it critically for important 
intellectual content: ES; JV; HS; MW; WL; RM; RG; CE. Approval of the final version to be submitted for publication: ES; JV; HS; MW; WL; RM; RG; CE. Accountable for all aspects of the work: ES; JV; HS; MW; WL; RM; RG; CE.

\section{Ethics approval and consent to participate}

The medical ethical board of the Radboud University Medical Center, Nijmegen concluded that the Dutch Medical Research Involving Human Subjects Act did not apply to this study (protocol number: 2015-1772 for sample 1 and protocol number 2016-2605 for sample 2). All participants provided informed consent.

\section{Consent for publication}

Not applicable.

\section{Competing interests}

All authors declare that they have no competing interests.

\section{Publisher's Note}

Springer Nature remains neutral with regard to jurisdictional claims in published maps and institutional affiliations.

\section{Author details}

'Department of Rheumatology, Sint Maartenskliniek, Sint Maartenskliniek, P.O Box 9011, 6500, GM, Nijmegen, The Netherlands. ${ }^{2}$ Department of Primary and Community Care, Radboud University Nijmegen Medical Center, Nijmegen, The Netherlands. ${ }^{3}$ Department of Orthopedics, Sint Maartenskliniek, Nijmegen, The Netherlands. ${ }^{4}$ Department of Rheumatology, Sint Maartenskliniek, Woerden, The Netherlands. ${ }^{5}$ Physical Therapy and Manual Therapy Velperweg Partnership, Arnhem, The Netherlands. ${ }^{6}$ Department of Psychology, Utrecht University, Utrecht, The Netherlands.

Received: 1 December 2016 Accepted: 14 September 2017

\section{Published online: 19 September 2017}

\section{References}

1. Bijlsma JW, Berenbaum F, Lafeber FP. Osteoarthritis: an update with relevance for clinical practice. Lancet. 2011:377:2115-26.

2. McAlindon TE, Bannuru RR, Sullivan MC, Arden NK, Berenbaum F, BiermaZeinstra SM, et al. OARSI guidelines for the non-surgical management of knee osteoarthritis. Osteoarthr Cartil. 2014;22:363-88.

3. Smink AJ, van den Ende CH, Vliet Vlieland TP, Swierstra BA, Kortland JH, Bijlsma JW, et al. "Beating osteoARThritis": development of a stepped care strategy to optimize utilization and timing of non-surgical treatment modalities for patients with hip or knee osteoarthritis. Clin Rheumatol. 2011;30:1623-9.

4. Zhang W, Moskowitz RW, Nuki G, Abramson S, Altman RD, Arden N, et al. OARSI recommendations for the management of hip and knee osteoarthritis, Part II: OARSI evidence-based, expert consensus guidelines. Osteoarthr Cartil. 2008;16:137-62

5. McHugh GA, Luker KA, Campbell M, Kay PR, Silman AJ. A longitudinal study exploring pain control, treatment and service provision for individuals with end-stage lower limb osteoarthritis. Rheumatology (Oxford). 2007;46:631-7.

6. Shrier I, Feldman DE, Gaudet MC, Rossignol M, Zukor D, Tanzer M, et al. Conservative non-pharmacological treatment options are not frequently used in the management of hip osteoarthritis. J Sci Med Sport. 2006;9:81-6.

7. Snijders GF, den Broeder AA, van Riel PL, Straten VH, de Man FH, van den Hoogen $\mathrm{FH}$, et al. Evidence-based tailored conservative treatment of knee and hip osteoarthritis: between knowing and doing. Scand J Rheumatol. 2011;40:225-31.

8. Otten R, van Roermund PM. Picavet HS: [Trends in the number of knee and hip arthroplasties: considerably more knee and hip prostheses due to osteoarthritis in 2030]. Ned Tijdschr Geneeskd. 2010;154:A1534.

9. Beswick AD, Wylde V, Gooberman-Hill R, Blom A, Dieppe P. What proportion of patients report long-term pain after total hip or knee replacement for osteoarthritis? A systematic review of prospective studies in unselected patients. BMJ Open. 2012;2:e000435.

10. Nilsdotter AK, Toksvig-Larsen S, Roos EM. Knee arthroplasty: are patients' expectations fulfilled? A prospective study of pain and function in 102 patients with 5-year follow-up. Acta Orthop. 2009;80:55-61.

11. Hofstede SN, Marang-van de Mheen PJ, Vliet Vlieland TP, van den Ende CH, Nelissen RG, van Bodegom-Vos L. Barriers and Facilitators Associated with Non-Surgical Treatment Use for Osteoarthritis Patients in Orthopaedic Practice. PLoS One. 2016;11:e0147406.
12. Tariman JD, Doorenbos A, Schepp KG, Becker PS, Berry DL. Patient, Physician and Contextual Factors Are Influential in the Treatment Decision Making of Older Adults Newly Diagnosed with Symptomatic Myeloma. Cancer Treat Commun. 2014:2:34-47.

13. Ajzen I. The Theory of Planned Behavior. Organ Behav Hum Decis Process 1991;50:179-211.

14. Uebelacker LA, Bailey G, Herman D, Anderson B, Stein M. Patients' Beliefs About Medications are Associated with Stated Preference for Methadone, Buprenorphine, Naltrexone, or no Medication-Assisted Therapy Following Inpatient Opioid Detoxification. J Subst Abus Treat. 2016;66:48-53.

15. Francis JJ, Wileman SM, Bekker H, Barton GR, Ramsay CR. Beliefs about surgery: Development and validation of an instrument to assess cognitive representations about surgery, in the context of a chronic illness. Psychol Health. 2009;24:1125-37.

16. O'Neill T, Jinks C, Ong BN. Decision-making regarding total knee replacement surgery: a qualitative meta-synthesis. BMC Health Serv Res. 2007;7:52

17. Selten EM, Vriezekolk JE, Geenen R, van der Laan WH, van der Meulen-Dilling RG, Nijhof MW, et al. Reasons for Treatment Choices in Knee and Hip Osteoarthritis: A Qualitative Study. Arthritis Care Res (Hoboken ). 2016;68:1260-7.

18. Smith TO, Purdy R, Lister S, Salter C, Fleetcroft R, Conaghan PG. Attitudes of people with osteoarthritis towards their conservative management: a systematic review and meta-ethnography. Rheumatol Int. 2014;34:299-313.

19. Benhamou M, Baron G, Dalichampt M, Boutron I, Alami S, Rannou F, et al. Development and validation of a questionnaire assessing fears and beliefs of patients with knee osteoarthritis: the Knee Osteoarthritis Fears and Beliefs Questionnaire (KOFBeQ). PLoS One. 2013;8:e53886.

20. Benhamou M, Boutron I, Dalichampt M, Baron G, Alami S, Rannou F, et al. Elaboration and validation of a questionnaire assessing patient expectations about management of knee osteoarthritis by their physicians: the Knee Osteoarthritis Expectations Questionnaire. Ann Rheum Dis. 2013:72:552-9.

21. Dima A, Lewith GT, Little P, Moss-Morris R, Foster NE, Hankins M, et al. Patients' treatment beliefs in low back pain: development and validation of a questionnaire in primary care. Pain. 2015;156:1489-500.

22. Horne R, Weinman J, Hankins M. The Beliefs about Medicines Questionnaire: the development and evaluation of a new method for assessing the cognitive representation of medication. Psychol Health. 1999:4:1-24.

23. Selten EMH, Vriezekolk JE, Nijhof MW, Schers HJ, Van der Meulen-Dilling RG, van der Laan WH et al. Barriers impeding the use of non-pharmacological, non-surgical care in hip and knee osteoarthritis: the views of general practitioners, physiotherapists and medical specialists. Journal of Clinical Rheumatology. 2017; in press.

24. Selten EM, Geenen R, van der Laan WH, van der Meulen-Dilling RG, Schers HJ, Nijhof MW, et al. Hierarchical structure and importance of patients' reasons for treatment choices in knee and hip osteoarthritis: a concept mapping study. Rheumatology (Oxford). 2017:56:271-8.

25. Streiner DL, Norman GR. Health Measurement Scales, a practical guide to their development and use. 4th ed. New York: Oxford University Press; 2008.

26. De Vet HCW, Terwee CB, Mokkink LB, Knol DL. Measurement in Medicine. 1st ed. New York: Cambridge University Press; 2011.

27. Willis GB, Artino AR Jr. What Do Our Respondents Think We're Asking? Using Cognitive Interviewing to Improve Medical Education Surveys. J Grad Med Educ. 2013;5:353-6.

28. Riemsma RP, Taal E, Rasker J, Houtman PM, VAn Paassen HC, Wiegman O. Evaluation of a Dutch version of the AIMS2 for patients with rheumatoid arthritis. Br J Rheumatol. 1996;35:755-60.

29. Bellamy N. The WOMAC Knee and Hip Osteoarthritis Indices: development, validation, globalization and influence on the development of the AUSCAN Hand Osteoarthritis Indices. Clin Exp Rheumatol. 2005;23:S148-53.

30. Costello AB, Osborne JW. Best Practices in Exploratory Factor Analysis: Four Recommendations for Getting the Most From Your Analysis. Pract Assess Res Eval. 2005;10

31. Tabachnick BG, Fidell LS. Using Multivariate Statistics. 5th ed. Boston: Allyn and Bacon; 2007.

32. Rankin G, Stokes M. Reliability of assessment tools in rehabilitation: an illustration of appropriate statistical analyses. Clin Rehabil. 1998;12:187-99.

33. Shrout PE, Fleiss JL. Intraclass correlations: uses in assessing rater reliability. Psychol Bull. 1979;86:420-8.

34. Terwee CB, Mokkink LB, Steultjens MP. Dekker J. Performance-based methods for measuring the physical function of patients with osteoarthritis of the hip or knee: a systematic review of measurement properties. Rheumatology (Oxford). 2006:45:890-902. 
35. Hawker GA. Who, when, and why total joint replacement surgery? The patient's perspective. Curr Opin Rheumatol. 2006;18:526-30

36. Ratcliffe J, Buxton M, McGarry T, Sheldon R, Chancellor J. Patients' preferences for characteristics associated with treatments for osteoarthritis. Rheumatology (Oxford). 2004;43:337-45.

37. Allen KD, Bosworth HB, Chatterjee R, Coffman CJ, Corsino L, Jeffreys AS, et al. Clinic variation in recruitment metrics, patient characteristics and treatment use in a randomized clinical trial of osteoarthritis management. BMC Musculoskelet Disord. 2014;15:413.

38. Jordan KP, Tan V, Edwards JJ, Chen Y, Englund M, Hubertsson J, et al. Influences on the decision to use an osteoarthritis diagnosis in primary care: a cohort study with linked survey and electronic health record data. Osteoarthr Cartil. 2016:24:786-93.

39. Musila N, Underwood M, McCaskie AW, Black N, Clarke A, van der Meulen $\mathrm{JH}$. Referral recommendations for osteoarthritis of the knee incorporating patients' preferences. Fam Pract. 2011;28:68-74.

40. Berger MJ, Kean CO, Goela A, Doherty TJ. Disease severity and knee extensor force in knee osteoarthritis: data from the Osteoarthritis Initiative. Arthritis Care Res (Hoboken). 2012;64:729-34.

41. Gronhaug G, Osteras N, Hagen KB. Quality of hip and knee osteoarthritis management in primary health care in a Norwegian county: a crosssectional survey. BMC Health Serv Res. 2014;14:598.

Submit your next manuscript to BioMed Central and we will help you at every step:

- We accept pre-submission inquiries

- Our selector tool helps you to find the most relevant journal

- We provide round the clock customer support

- Convenient online submission

- Thorough peer review

- Inclusion in PubMed and all major indexing services

- Maximum visibility for your research

Submit your manuscript at www.biomedcentral.com/submit
Biomed Central 